\title{
Multi-unit response correlations along the tonotopic gradient and within isofrequency laminae of the inferior colliculus
}

Dominika Lyzwa ${ }^{1 *}$, J Michael Herrmann ${ }^{2}$

From Twenty Second Annual Computational Neuroscience Meeting: CNS*2013

Paris, France. 13-18 July 2013

Within the central auditory system, the central nucleus of the inferior colliculus (ICC) is a station where all stimulus information converges. Furthermore, it is a target for auditory prostheses due to its tonotopic order and surgical accessibility [1]. To better understand the functional organization of this important nucleus, response similarity along the frequency gradient and within iso-frequency laminae were investigated. Furthermore, the neural discrimination was compared between pooled simultaneous and non-simultaneous responses.

Vocalizations, being natural stimuli and showing a variety of spectral and temporal modulations, are particularly interesting and can elicit responses which are not triggered by pure tones, clicks, white noise or other artificial simplified sounds [2]. Conspecific vocalizations (at intensity levels of 30-70 db) were presented monaurally to guinea pigs while recording multi-unit activity from the contralateral ICC. Data were simultaneously recorded from 32 positions either along the tonotopic gradient using double shank electrodes or within two iso-frequency lamina using double tetrode electrodes.

We investigated response similarity along these two dimensions of the ICC for multi-unit thresholded spike trains, local field potentials and voltage traces. We evaluated the correlation dependencies of multi-unit pairs on their spatial distance, difference in best-frequency and similarity of the frequency tuning curves. The presence of a distributed code would imply that the interplay of several multi-units leads to better representation of the complex sound. We have tested this by comparing neural discrimination between pooled sets of simultaneously recorded responses to non-simultaneously recorded ones. The latter was obtained by randomly shuffling the trials. We used linear discriminant analysis for the classification. The extracted features were firing rates of time windows over the duration of the longest vocalizations.

We found that the averaged correlation of single spiketrains is much lower than correlation of poststimulus

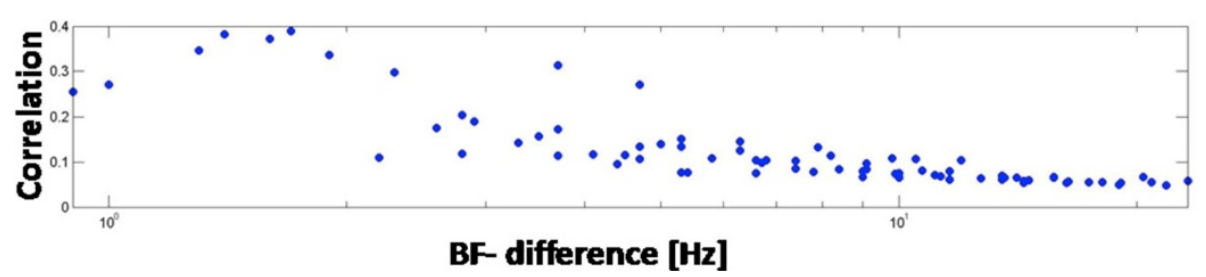

Figure 1 Correlation for multi-units along the tonotopic gradient versus logarithmically scaled difference in best frequency. Correlation decreases with BF-distance.

\footnotetext{
* Correspondence: dominika@nld.ds.mpg.de

'Dept. of Nonlinear Dynamics, Max Planck Inst. for Dynamics and Self-

Organization, Göttingen, 37077, Germany

Full list of author information is available at the end of the article
}

(c) 2013 Lyzwa and Herrmann; licensee BioMed Central Ltd. This is an Open Access article distributed under the terms of the Creative 
time histograms (PSTH). This is partly due to the high trial-trial variability which is averaged out in the PSTHs. Correlation decreases with distance (' $\mu \mathrm{m}$ ' and 'best frequency') along the tonotopic gradient, see Figure 1. Within an iso-frequency lamina though it does not decrease with $\mu$ m-distance. This redundancy within the iso-frequency laminae but not along the tonotopic gradient has implications for arrays to electrically stimulate the ICC.

There is no significant difference in neural discrimination performance for simultaneous and non-simultaneous responses which could be found from the multi-unit responses.

\section{Acknowledgements}

This work was supported by the BMBF in the National Network for Computational Neuro-science, grant number \#01GQ0811 to BFNT Göttingen. We would like to thank Thilo Rode, Tanja Hartmann, and Hugh H. Lim for the guinea pig recordings and vocalizations.

\section{Author details}

${ }^{1}$ Dept. of Nonlinear Dynamics, Max Planck Inst. for Dynamics and SelfOrganization, Göttingen, 37077, Germany. ${ }^{2}$ Institute of Perception, Action and Behaviour, University of Edinburgh, Edinburgh, EH 8 9AB, UK.

Published: 8 July 2013

\section{References}

1. Reuter G, Patrick JF, Lenarz M, Lenarz T, Lim HH: The auditory midbrain implant: a new auditory prosthesis for neural deafness-concept and device description. Otol Neurotol 2006, 6:838-843.

2. FE Theunissen, $\mathrm{K}$ Sen, Doupe $A H$ : Spectral-temporal receptive fields of nonlinear auditory neurons obtained using natural sounds. J of Neurosci 2000, 20(6):2315-2331.

doi:10.1186/1471-2202-14-S1-P169

Cite this article as: Lyzwa and Herrmann: Multi-unit response correlations along the tonotopic gradient and within isofrequency laminae of the inferior colliculus. BMC Neuroscience 2013 14(Suppl 1): P169.

\section{Submit your next manuscript to BioMed Central} and take full advantage of:

- Convenient online submission

- Thorough peer review

- No space constraints or color figure charges

- Immediate publication on acceptance

- Inclusion in PubMed, CAS, Scopus and Google Scholar

- Research which is freely available for redistribution

Submit your manuscript at www.biomedcentral.com/submit 